GLOBAL JOURNAL OF COMMUNITY MEDICINE VOL. 2 NO. 1 \& 2 2009: 61 - 64 COPYRIGHT@ BACHUDO SCIENCE CO. LTD PRINTED IN NIGERIA. ISSN 1597 - 9857

\title{
THE UNBOOKED PREGNANT WOMAN: EXPERIENCE FROM A RURAL TERTIARY HOSPITAL SOUTH-SOUTH NIGERIA.
}

\section{A. M. ABASIATTAI AND E. J. UDOMA}

(Received 16 October, 2008; Revision Accepted 20 August, 2009)

\begin{abstract}
This retrospective study was carried out to determine the obstetric outcome of unbooked pregnant women who presented at the University of Uyo Teaching Hospital over a five year period. Five thousand nine hundred and sixty two women presented at the labour ward out of which $617(10.3 \%)$ were unbooked. Majority of the patients were multiparous $(61.2 \%)$ and the most common clinical presentations were obstructed labour (28.8\%) and eclampsia (19.8\%). There were 255 still births and 5 early neonatal deaths resulting in a perinatal mortality rate of $420 / 1000$. Maternal mortality ratio was $7,800 / 100,000$ live births and this was mostly from eclampsia $(28.8 \%)$ and obstetric haemorrhage $(19.8 \%)$. Grass-root education in our various communities highlighting the importance and advantages of formal antenatal care and the inclusion of this in the health education curriculum of primary and secondary schools is advocated.
\end{abstract}

KEY WORDS: Unbooked pregnant women, Uyo, obstetric outcome

\section{INTRODUCTION}

Antenatal care (ANC) is a specialized pattern of care organised for pregnant women to enable them attain and maintain a state of good health throughout pregnancy (Onajole et al 2005). It is an indispensable part of effective maternity care service that also helps improve the chances of having safe delivery of healthy infants (Gharoro and Okonkwo 1999). It is a form of preventive medicine and an important component of maternal health. The range of activities covered by ANC includes nutrition, education, tetanus vaccination, malaria prevention and treatment, HIV information and prevention of mother to child transmission (PMTCT) services and services for monitoring of potential complications (Shah and Say 2007). In addition, ANC helps maintain a woman's health, prevents anaemia, confirms normal progress including normal fetal growth and facilitates the diagnosis of some of the complications of pregnancy (Ekwempu 1988).

Currently, quality ANC has been confirmed in several reports to prevent majority of maternal and perinatal mortality and morbidity and is one of the major factors contributing to the reduction of maternal deaths in industrialized countries (Shah and Say 2007). Even a single antenatal visit as compared to no visit has been reported to significantly reduce the risk of maternal mortality. Currently, the World Health Organisation (WHO) recommends at least four antenatal care visits with trained health personnel during normal pregnancy (Shah and Say 2007).

Studies from different centers in Nigeria continue to show high maternal and perinatal morbidity and mortality among women who do not have formal ANC (Abasiattai and Umoiyoho 2009, Uzoigwe and John 2000). Also, preliminary observational studies indicate that a significant proportion of obstetric emergencies at the University of Uyo Teaching Hospital, Uyo occur in unbooked pregnant women (Abasiattai and Umoiyoho 2009). Hence this retrospective review was carried out to unfold our experience with unbooked pregnant women who present in our center.

\section{MATERIALS AND METHODS}

\section{Setting}

This study was conducted at the maternity unit of the University of Uyo Teaching

A. M. Abasiattai, Dept. of Obstetrics \& Gynaecology, University of Uyo Teaching Hospital, Uyo, Nigeria

E. J. Udoma, Department of Obstetrics \& Gynaecology, University of Calabar Teaching Hospital, Calabar, Nigeria 
Hospital (UUTH), located in Uyo, the capital of Akwa Ibom State in the South-South geopolitical zone of Nigeria. The hospital is the only health facility that offers tertiary health care services in the state with a population of 3.92 million people (Abasiattai and Umoiyoho, 2009). The maternity unit of the hospital has 63 beds with an annual delivery rate of about 1,500 . The hospital has 3 antenatal clinic sessions a week with an average clinic attendance of about 140 women. ANC is provided routinely for all patients who present themselves for it and also for those with high risk pregnancies referred to the center.

\section{Methods}

The registration numbers of all unbooked patients who presented in the hospital from $1^{\text {st }}$ January 2004-31 ${ }^{\text {st }}$ December 2008 were extracted from the labour ward register. With the numbers, their case records were obtained for indepth study. Information abstracted included their demographic data, reasons for not booking, presentation, mode of delivery, and maternal and perinatal outcome. The data were analysed using simple proportion, rates and tables.

For the purpose of this study, a patient is considered unbooked if she had not been attended to by any medical personnel throughout her pregnancy.

\section{RESULTS}

During the study period 5,962 women presented at the labour ward of UUTH out of which six hundred and seventeen patients (10.3\%) were unbooked and thus had no formal ANC. The ages and parity of the patients are shown in table I. Majority of the patients were aged between 21-30 years $379(60.0 \%)$ and were multiparous $378(61.2 \%)$-table 1.

The most common clinical presentations were obstructed labour 174 (28.8\%) and eclampsia $122(19.8 \%)$ while the least were retained placenta $6(1.0 \%)$ and cord prolapse 1 $(0.2 \%)$ - table 2.

Two hundred and ninety patients $(47.0 \%)$ were delivered by emergency caesarean section (CS) while $202(32.7 \%)$ had spontaneous vaginal delivery (SVD). Nine $(1.5 \%)$ patients had breech extraction while $7(1.1 \%)$ had their fetuses delivered by craniotomy-table 3 .

There were 255 still births (41.3\%), 112 (43.9) of which were already macerated. Three hundred and fifty nine babies $(58.2 \%)$ were delivered alive out of which $90(14.6 \%)$ were severely asphyxiated. Five babies died within 24 hours of birth. The perinatal mortality rate (PNMR) was 420/1000.

There were 48 maternal deaths resulting in a maternal mortality ratio of $7800 / 100,000$ live births. Twenty one deaths $(3.4 \%)$ were from eclampsia, $12 \quad(1.9 \%)$ from obstetric haemorrhage, $10(1.6 \%)$ from ruptured uterus while $5(0.8 \%)$ were from puerperal sepsis.

Table 1: Age and parity of the patients $\mathrm{N}=617$

\begin{tabular}{ll}
\hline Variable & No (\%) \\
Age & \\
$\leq 20$ & $123(19.9)$ \\
$21-25$ & $196(31.8)$ \\
$26-30$ & $183(29.7)$ \\
$31-35$ & $74(12.0)$ \\
$36-40$ & $24(3.9)$ \\
Not recorded & $17(2.8)$ \\
Parity & $150(24.3)$ \\
Po & $376(61.2)$ \\
P1-4 & $54(8.8)$ \\
$\geq$ P5 & $35(5.7)$ \\
Not recorded & \\
\hline
\end{tabular}

Table 2: Clinical presentation $\mathrm{N}=617$

\begin{tabular}{ll}
\hline Presentation & No (\%) \\
Obstructed labour & $174(28.2)$ \\
Eclampsia & $122(19.8)$ \\
Intrauterine fetal death & $116(18.8)$ \\
Normal labour & $65(10.5)$ \\
Ruptured uterus & $46(7.5)$ \\
Malpresentation & $38(6.2)$ \\
Antepartum haemorrhage & $25(4.1)$ \\
Retained second twin & $9(1.5)$ \\
Hand prolapse & $8(1.3)$ \\
Retained placenta & $6(1.0)$ \\
Cord prolapse & $190.2)$ \\
Not recorded & $7(1.1)$ \\
\end{tabular}


Table 3: Mode of delivery $\mathrm{N}=617$

\begin{tabular}{ll}
\hline $\begin{array}{l}\text { Mode of delivery } \\
\text { Emergency caesarean section }\end{array}$ & No (\%) \\
$\begin{array}{l}\text { (47.0) } \\
\text { Spontaneous vaginal delivery }\end{array}$ & 290 \\
$\begin{array}{l}\text { (32.7) } \\
\text { Laparotomy }\end{array}$ & 202 \\
Vacuum extraction & $46(7.5)$ \\
Assisted breech delivery & $42(6.8)$ \\
Breech extraction & $21(3.4)$ \\
Craniotomy & $9(1.5)$ \\
\end{tabular}

\section{DISCUSSION}

This study reveals a poor obstetric outcome in unbooked patients who present in our center. Sadly, twenty years after the safe motherhood initiative was launched in Nairobi, Kenya, despite all the training of more manpower and establishment of more health care facilities, some pregnant women in our environment still do not obtain formal ANC and contribute significantly to Nigeria's high maternal and perinatal morbidity and mortality.

The percentage of women who presented as unbooked emergencies in our study is similar to what obtains in other centers in Nigeria (lloabachie 1988, Okogbenin et al 2007) but at variance with what obtains in East Africa where antenatal clinic attendance is reportedly high ( Van Eijk et al 2006). In a rural area in Western Kenya, 9 out of 10 women reported at least one antenatal clinic visit during their last pregnancy (Van Eijk et al 2006). Reasons documented by Nigerian women for not utilizing orthodox ANC services include husband's disapproval, lack of transport, religious reasons, cultural barriers, cost and negative attitude of health staff (Salako et al 2006, Okonkwo and Ngene 2004). However, nation-wide community based studies evaluating perception and attitude of women towards formal ANC are certainly needed.

Obstructed labour and eclampsia were the most common modes of presentation. Several studies have shown a direct proportional relationship between lack of ANC and obstructed labour and eclampsia (Fasubaa et al 1999, Bassey et al 2005, Olatnuji and Sule-Odu 2007). Obtaining formal ANC ensures pregnant women appreciate the advantages of delivering in proper orthodox health facilities where feto pelvicdisproportion would be diagnosed early and caesarean section carried out before obstruction with all its attendant sequelae sets in. In almost all cases, eclampsia is preceded by signs of preeclampsia which would be detected by good antenatal checks (Olatunji and Sule-Odu 2007). In addition ANC provides an opportunity for proper screening, early recognition and provision of appropriate care for those patients with classical signs and symptoms of pre-eclampsia (Bassey et al 2005). Currently, focused ANC; an updated approach to ANC that emphasizes quality of visits rather than quantity has been developed by the World Health Organization (WHO) and is promoted in the developing countries. This new model which is designed to increase antenatal clinic attendance recommends a total of four antenatal visits and has been found to improve quality while reducing cost of care. In addition, it produces similar maternal and perinatal outcome when compared with the standard model (WHO 2002).

The maternal and perinatal outcome were very poor as almost half of the babies delivered were still born and about a quarter of those born alive were severely asphyxiated at birth. In-addition, the maternal mortality which was mainly from eclampsia and obstetric haemorrhage was also very high. The patients were brought to hospital in moribund states after several fits had occurred or in irreversible shock, after bleeding for several hours without any form of resuscitation.

In conclusion, the results of our study reveal the need to refocus and re-emphasize universal ANC as a major gateway to reducing maternal and perinatal mortality in our country. Grass root education in our various communities highlighting the importance and advantages of formal ANC should be prioritized and should also be included in the health education curriculum of both primary and secondary schools. Community and political leaders should be made to see the need to encourage members of their community to obtain formal ANC. A significant reduction in the number of unbooked emergencies will increase the antenatal clinic attendance and hospital delivery rates and ultimately help to reduce the country's high maternal and perinatal mortality rate.

\section{ACKNOWLEDGEMENT}

We are grateful to Prof. S Etuk for reading through the manuscript. 


\section{REFRENCES}

Abasiattai, A. M. and Umoiyoho, A. J., 2009. A 6 year review of maternal deaths in a teaching hospital in South-South Nigeria. The Internet J Gyne Obstet, 11: 1.

Bassey, E. A., Abasiattai, A. M., Umoiyoho, A. H. and Udoma, E. J., 2005. Presentation and outcome of eclampsia in Uyo, Nigeria. Trop J Med Research; 9 (2): 9-11.

Ekwempu, C. C., 1988. The influence of Antenatal care on pregnancy outcome. Trop J Obstet Gynaecol; 1 (1): 67-70.

Fasubaa, O. B., Ogunniyi, S. O., Omale, A. E. and Owolabi, A.T., 1999. Analysis of obstructed labour in Wesley Guild hospital, Ilesha, Nigeria. Nig J Clin Practice; 2 (2): 39-41.

Gharoro, E. P. and Okonkwo, C. A., 1999. Changes in service organisation: Antenatal care policy to improve attendance and reduce maternal mortality. Trop J Obstet Gynaecol; 16 (1): 21-25.

lloabachie, G. C., 1988. Maternity care monitoring: The case of the unbooked patient. Trop J Obstet Gynecol; 1 (1): 6568.

Okogbenin, S. A., Okonta, P. I., Eigbefoh, J. and Okusanya, B. O., 2007. The demographic characteristics and health seeking behaviour of unbooked patients in Irrua specialist teaching hospital. Nig J Med; 16 ((1): 65-70.

Okonkwo, J. E. N. and Ngene, J. N., 2004. Determinants of poor utilization of orthodox health facilities in a Nigerian rural community. Nig J Clin Practice; 7 (2): 74-78.

Olatunji, A. O. and Sule-Odu, A. O., 2007. Presentation and outcome of Eclampsia at a Nigerian University teaching hospital. Nig J Clin Practice; 10 (1): 1-4.

Onajole, A. T., Ali, F. A., Odeyemi, K. A., Ogunnowo, B. O. and Oriodota, E. S., 2005. Perceived cost in the utilization of antenatal care services by pregnant women in Abeokuta South local Government area of Ogun state. Nig Med Practitioner 48 (4): 98-102.

Salako, A. A, Oloyede, O. A. and Odusoga, O. L., 2006. Factors influencing non-utilization of maternity care services in Sagamu, South-Western Nigeria. Trop J Obstet Gynaecol; 23 (1): 48-53.

Shah, I. H. and Say, L., 2007. Maternal mortality and maternity care from 1990 to 2005: Uneven but important gains. Reprod Health Matters; 15 (30); 17-27.

Uzoigwe, S. A. and John, C. T., 2000. A Ten-year review of maternal mortality at PortHarcourt, Nigeria. Nig J Clin Practice; 3 (2): 80-84.

VanEijk, A. M., Bles, H. M., Odhiambo, F., Ayisi, J. G., Blokland, I. E. and Rosen, D.,H et al. 2006. Use of antenatal services and delivery care among women in rural Western Kenya: a community based survey. Reprod Health; 3: 2.

World Health Organisation., 2002. WHO antenatal care randomized trial; Manual for the implementation of the new model. Geneva; WHO programme to map best reproductive health practices. 